\title{
Understanding Gluten Sensitivity and Celiac Disease ${ }^{1}$
}

\author{
Stephanie Meyer, Karla P. Shelnutt, and Gail P. A. Kauwell ${ }^{2}$
}

Several years ago, most people probably had never heard of gluten, but by 2011, gluten-free diets became more popular than low carbohydrate diets (Sapone et al., 2012). Gluten-free diets surged in popularity for many reasons, but one is the increased awareness and diagnosis of conditions in which gluten triggers an abnormal response in the body. These conditions include gluten sensitivity and celiac disease. This publication will help you learn about gluten sensitivity and celiac disease, as well as understand what they have in common and what is different about them. Neither of these conditions is the same as a food allergy. For information about food allergies, see the EDIS publication FY1282/FCS8997 Raising Healthy Children: Food Allergies (http://edis.ifas.ufl.edu/fy1282).

\section{What Is Gluten and Where Is It Found?}

Gluten is the major protein in wheat (Sapone et al., 2012). This protein has special properties that give bread its doughy texture and baked goods their chewiness. Gluten is also present in rye, barley, and products made with these grains. Wheat, rye, and barley are used to make many different foods, including cereals, cakes, cookies, pasta, salad dressings, sauces, and more.

\section{Is Gluten Harmful?}

Gluten is not harmful to most people. Only people with gluten sensitivity or celiac disease need to avoid glutencontaining foods. When people with these conditions eat gluten, they usually develop stomach and intestinal pain, bloating, diarrhea, or constipation (Volta et al., 2011; Volta \& De Grigio, 2012). Other symptoms that may occur include fatigue, skin rashes, headaches, joint pain, leg or arm numbness, depression, and anemia (Sapone et al., 2012; Sapone et al., 2011; Volta \& De Grigio, 2012).

\section{What Is Gluten Sensitivity?}

Gluten sensitivity is a condition that results in an adverse reaction to foods containing gluten, such as wheat, rye, and barley. Both gluten sensitivity and celiac disease involve an immune system response and may have similar symptoms; however, the type of immune response is different, and people with gluten sensitivity do not develop severe intestinal damage like that seen in patients with celiac disease. In fact, until 2000, doctors and scientists did not recognize the existence of gluten sensitivity (Cooper et al., 1980; Kaukinen et al., 2000).

As a result, patients with symptoms similar to celiac disease who didn't have any damage to their intestines were often sent to a psychiatrist (Verdu, Armstrong, \& Murray, 2009). To relieve their symptoms, many patients removed gluten from their diets and had good results. Many doctors then recognized that reactions to gluten were possible without having celiac disease (Sapone et al., 2012).

There are no specific laboratory tests for diagnosing gluten sensitivity. The first step to determine if you have gluten sensitivity is to make sure you do not have celiac disease.

1. This document is FCS80028, one of a series of the Department of Family, Youth, and Community Sciences, Florida Cooperative Extension Service, Institute of Food and Agricultural Sciences, University of Florida. First published April 2013. Please visit the EDIS website at http://edis.ifas.ufl.edu.

2. Stephanie Meyer, dietetic intern, Master of Science-Dietetic Internship Program, Food Science and Human Nutrition Department; Karla P. Shelnutt, PhD, RD, assistant professor, Department of Family, Youth and Community Sciences; Gail P.A. Kauwell, PhD, RD, professor, Food Science and Human Nutrition Department; Florida Cooperative Extension Service, Institute of Food and Agricultural Sciences, University of Florida, Gainesville, FL 32611. 
If you do not meet the criteria for a diagnosis of celiac disease, then eliminate gluten from your diet to see if your symptoms improve once it is no longer part of your diet. If you suspect you have gluten sensitivity, you should consult your primary care provider or a registered dietitian (RD) before altering your diet.

The only way to manage gluten sensitivity is to avoid gluten by following a gluten-free diet (Sapone et al., 2012). With gluten sensitivity, you may be able to add gluten back to your diet with time, but you must avoid all gluten while on the gluten-free diet to prevent symptoms from occurring (Sapone et al., 2012). No drugs or medications are available to treat gluten sensitivity.

\section{What Is Celiac Disease?}

Celiac disease affects 1 in 130 Americans (Fasano et al., 2003). It is caused by a combination of genetic factors and environmental triggers. People who have certain variations in their genes are at risk for developing celiac disease when they eat foods containing gluten. This results in an autoimmune reaction, a type of reaction that occurs when the body attacks itself. Because of this reaction, the intestinal tract is damaged. This damage affects how food is absorbed and can lead to many symptoms of celiac disease. Although these symptoms are very similar to gluten sensitivity, damage to the intestines and the resulting loss of function are specific to celiac disease.

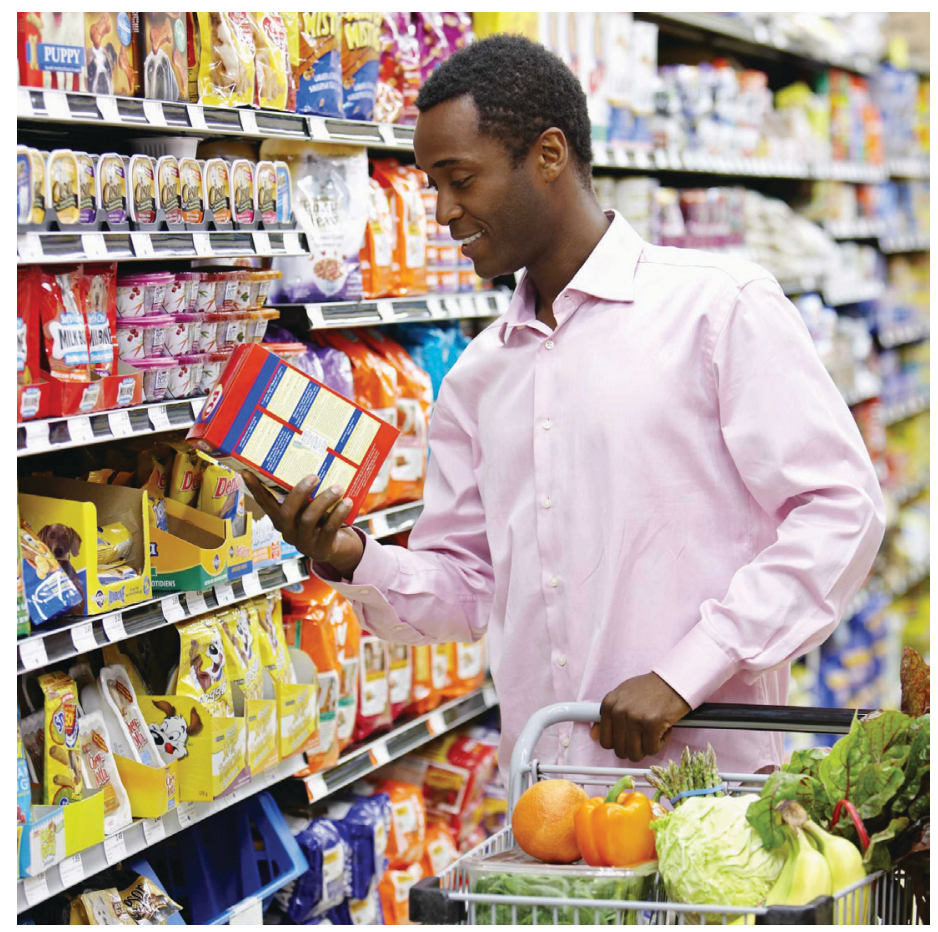

Figure 1. If you have celiac disease or gluten sensitivity, you should read ingredient labels to follow a gluten-free diet.

Credits: Fuse
The onset of celiac disease can occur weeks to years after exposure to gluten. It is diagnosed by doing blood tests and taking a sample of the lining of the small intestine to see if damage has occurred (Caja, Mäki, Kaukinen, \& Lindfors, 2011). Celiac disease is not a food allergy, and it is more severe than gluten sensitivity and cannot be outgrown. The only way to treat celiac disease is with a gluten-free diet, but unlike gluten sensitivity, gluten should never be returned to the diet (Sapone et al., 2012).

\section{What Is a Gluten-Free Diet?}

Knowing what to eat if you have celiac disease or gluten sensitivity is essential to ensuring success on a gluten-free diet. A gluten-free diet excludes all foods that contain gluten. If you are unsure if a food contains gluten, reading the ingredients list will help you know if the food is safe to eat. Food manufacturers are required to list each ingredient in a food in the ingredients list. When following a gluten-free diet, you must read the list carefully because any amount of gluten can cause a reaction in people with celiac disease or gluten sensitivity.

The word gluten is not usually listed in the ingredients list, so you will need to know which ingredients contain gluten. Table 1 provides a list of gluten-containing and gluten-free grains. Foods made with gluten-containing grains or ingredients made from these grains, such as malt and malt vinegar, should be avoided on a gluten-free diet. While some gluten-containing foods such as bread, pasta, pastries, cookies, and many cereals are easy to identify, other gluten sources such as beer, soy sauce, and condiments are less obvious. You should be cautious of foods that contain ingredients such as hydrolyzed plant proteins if the source is not specified. For example, an ingredients list that says "hydrolyzed plant protein" but does not specify the source of the plant protein may or may not contain gluten. However, a label that says "hydrolyzed plant protein (soy)" clearly identifies soy as the source of plant protein. Also, note that a wheat-free product may not necessarily be gluten free (Spaulding-Albright \& Kupper, 2010).

Refer to Table 1 for a list of gluten-free grains. These can serve as great substitutes for grains that contain gluten. Numerous gluten-free products are available at supermarkets or specialty food stores. Make sure to read the ingredients list on products to be certain they are glutenfree because there is currently no regulation on gluten-free products. Naturally gluten-free grains may contain gluten if they are processed using the same equipment as products containing gluten. Some manufacturers produce their products in facilities separate from those where wheat and 
other gluten-containing grains are processed. If you are unsure about the products you are purchasing, contact the manufacturer and ask if a "dedicated facility" or "dedicated line" is used to process gluten-free products.

Table 1. Gluten-Containing and Gluten-Free Grains ${ }^{1}$

\begin{tabular}{|l|l|}
\hline Gluten-Containing Grains & Gluten-Free Grains \\
\hline Wheat & Amaranth \\
\hline Rye & Arrowroot \\
\hline Burley & Bean flours \\
\hline Couscous & Buckwheat \\
\hline Durum & Corn \\
\hline Farina & Millet \\
\hline Kamut & Nut flours \\
\hline Semolina & Quinoa \\
\hline Spelt & Rice \\
\hline Triticale & Soy \\
\hline White flour & Sorghum \\
\hline Wheat bran & Tapioca \\
\hline Wheat germ & Teff \\
\hline $\begin{array}{l}\text { 'American Diabetes Association, } \\
2010\end{array}$ & Kasha \\
\hline
\end{tabular}

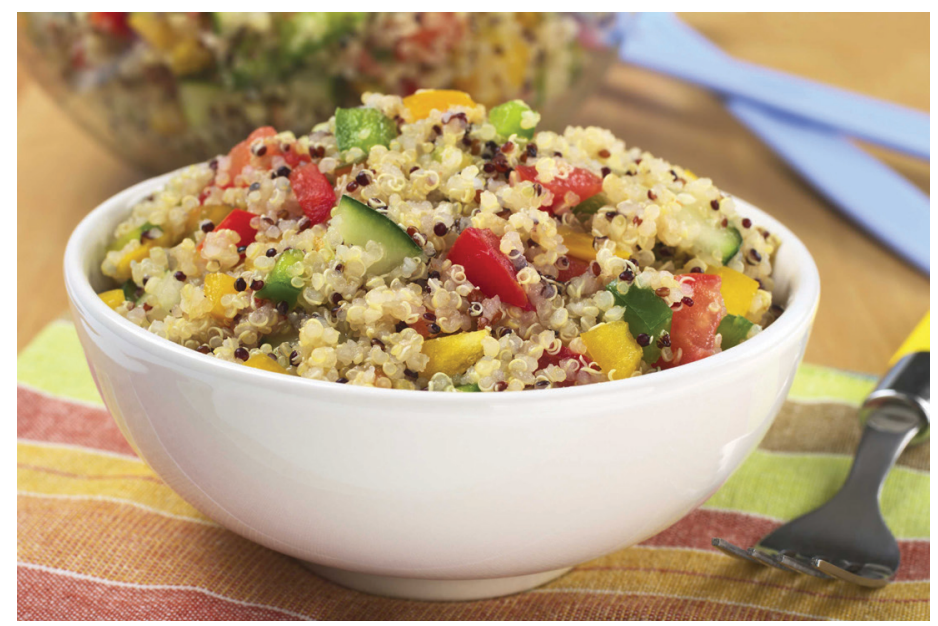

Figure 2. Quinoa is a good example of a gluten-free grain. To learn more about gluten-free grains, see Table 1 in this publication. Credits: iStockphoto

\section{Should You Follow a Gluten-Free Diet?}

If you think you may be experiencing a problem with gluten, you should talk with your doctor before starting a gluten-free diet. Following the diet before being tested for celiac disease can yield false-negative results. Following a gluten-free diet may also be expensive. If you are avoiding gluten and don't need to be, you may be wasting money. Some doctors may recommend eliminating dairy in addition to gluten to treat gluten sensitivity. Eliminating dairy may not be necessary if you only have gluten sensitivity, and it may lead to nutritional deficiencies. If you are testing to see if a gluten-free diet will relieve symptoms, make sure to only eliminate gluten to determine if gluten is indeed causing the symptoms. Eliminating more than one food or food group at a time (such as eliminating gluten and dairy at the same time) could lead to inaccurate conclusions. When following a gluten-free diet or any new diet, you should see a registered dietitian to ensure you are on the right track and getting enough of the nutrients you need.

\section{Summary}

Gluten sensitivity and celiac disease have similar symptoms and the same treatment. However, gluten sensitivity and celiac disease are very different in terms of what causes the condition and the type and amount of damage that occurs in the intestinal tract. Currently, the only way to manage gluten sensitivity and celiac disease is by following a glutenfree diet. If you think you may be experiencing symptoms of gluten sensitivity or celiac disease, contact a physician and registered dietitian before altering your diet.

\section{Recommended Resources}

To learn more about gluten sensitivity and other nutritionrelated topics, contact the Family and Consumer Sciences (FCS) agent at your county Extension office (visit http:// solutionsforyourlife.ufl.edu/map/ to find your local office). A registered dietitian also can provide you with reliable information on nutrition.

American Diabetes Center - Gluten-Free Diets: This website provides resources and tips for healthy eating and meal planning on a gluten-free diet. http://www.diabetes.org/ food-and-fitness/food/planning-meals/gluten-free-diets/.

Celiac Disease Foundation: This website provides information, news, and resources for celiac disease patients. It also provides information about local support for the disease and a gluten-free resource directory frequently updated with new gluten-free products. http://www.celiac.org/.

\section{References}

American Diabetes Association. (2012). What foods have gluten? Retrieved from http://www.diabetes.org/food-andfitness/food/planning-meals/gluten-free-diets/what-foodshave-gluten.html 
Caja, S., Mäki, M., Kaukinen, K., \& Lindfors, K. (2011).

Antibodies in celiac disease: Implications beyond diagnos-

tics. Cell. Mol. Immunol. 8(2), 103-109.

Cooper, B. T., Holmes, G. K., Ferguson, R., Thompson, R. A., Allan, R. N., \& Cooke, W. T. (1980). Gluten-sensitive diarrhea without evidence of celiac disease. Gastroenterology 79(5 Pt 1), 801-806.

Fasano, A., Berti, I., Gerarduzzi, T., Not, T., Colletti, R. B., Drago, S., et al. (2003). Prevalence of celiac disease in at-risk and not-at-risk groups in the United States: A large multicenter study. Arch Intern Med. 163(3), 286-292.

Kaukinen, K., Turjanmaa, K., Mäki, M., Partanen, J., Venäläinen, R., Reunala, T., \& Collin, P. (2000). Intolerance to cereals is not specific for coeliac disease. Scand. J. Gastroenterol. 35(9), 942-946.

Sapone, A., Bai, J. C., Ciacci, C., Dolinsek, J., Green, P. H. R., Hadjivassiliou, M., et al. (2012). Spectrum of glutenrelated disorders: Consensus on new nomenclature and classification. BMC Med. 10, 13.

Sapone, A., Lammers, K. M., Casolaro, V., Cammarota, M., Giuliano, M. T., De Rosa, M., et al. (2011). Divergence of gut permeability and mucosal immune gene expression in two gluten-associated conditions: Celiac disease and gluten sensitivity. BMC Med. 9, 23.

Spaulding-Albright, N., \& Kupper, C. (2010). Nutrition education for gluten-free diet. Florida Dietetic Association Manual of Medical Nutrition Therapy 24, 1046-1055.

Verdu, E. F., Armstrong, D., \& Murray, J. A. (2009). Between celiac disease and irritable bowel syndrome: The "no man's land" of gluten sensitivity. Am. J. Gastroenterol. 104(6), 1587-1594.

Volta, U., \& De Giorgio, D. (2012). New understanding of gluten sensitivity. Nat Rev Gastroenterol Hepatol. 9(5):295-300.

Volta, U., Tovoli, F., Cicola, R., Parisi, C., et al. (2011). Serological tests in gluten sensitivity (nonceliac gluten intolerance). J. Clin. Gastroenterol. 46(8), 680-685. 